\title{
Long-term efficacy and safety of lamotrigine:
} Results from the open-label extension of the

\section{lamotrigine monotherapy study in adult Japanese patients with epilepsy}

Takamichi Yamamoto ${ }^{1}$, Masahiro Shimizu ${ }^{2}$, Katsuaki Sato $^{2}$, Atsuyo Kurata ${ }^{2}$, Yotaro Numachi ${ }^{2}$

${ }^{1}$ Seirei Hamamatsu General Hospital, Hamamatsu, Japan

${ }^{2}$ GlaxoSmithKline, Tokyo, Japan

Clinical Trial Registration Number: NCT01431963.

URL: https://clinicaltrials.gov/ct2/show/NCT01431963?term=lamotrigine\&rank=84

Key Words: Lamotrigine, monotherapy, newly diagnosed epilepsy, recurrent epilepsy

Received: March 14, 2016; Accepted: March 4, 2017

\begin{abstract}
To investigate the efficacy and safety of long-term lamotrigine monotherapy, 22 Japanese patients (19 with newly diagnosed epilepsy and 3 with recurrent epilepsy) were enrolled in the extension phase of the study after completion of 30 weeks of lamotrigine treatment. More than $80 \%$ of patients remaining at each time point achieved seizure-free status at all time points up to week 120 in the extension phase. No unexpected adverse events were reported. Our findings suggest that long-term lamotrigine monotherapy appears to be effective and generally well tolerated in adult Japanese patients with partial seizures and generalized tonic-clonic seizures.
\end{abstract}




\section{Introduction}

Lamotrigine was launched in 2008 as adjunct therapy for epilepsy in Japan. A clinical study of lamotrigine monotherapy in epilepsy patients was started in September 2011. We have previously reported the efficacy and safety of lamotrigine monotherapy administered for up to 30 weeks (including the dose escalation and maintenance phases) in Japanese and Korean adult patients with newly diagnosed epilepsy or recurrent epilepsy [1]. Japanese patients who completed 30 weeks of treatment with lamotrigine monotherapy in the study were eligible to enter an extension phase aiming to assess the long-term tolerability and efficacy of lamotrigine. This paper describes the long-term efficacy and safety of lamotrigine monotherapy for up to 1055 days.

\section{Methods}

After completion of the initial phase of study [1] and having provided additional written informed consent, Japanese subjects who had partial seizures (including secondarily generalized seizures) or generalized tonicclonic seizures and who had responded to lamotrigine without tolerability issues by investigator's judgment were eligible to enter the extension phase. In the extension phase, subjects visited the clinic every 12 weeks for assessment of efficacy and safety. Patients in the extension phase could continue to receive lamotrigine monotherapy until the Japanese Regulatory Authority approved the monotherapy indication for partial seizures and generalized tonic-clonic seizures in Japanese adults. In the case of discontinuation in the extension phase, lamotrigine was tapered and the post-study examination was performed within 1-4 weeks after the last dose of the investigational product.

During the extension phase, the doses of lamotrigine varied from 100 to $400 \mathrm{mg} /$ day once or twice a day depending on the subject's seizure status and safety. When dose reduction to below $100 \mathrm{mg} /$ day or escalation to above $400 \mathrm{mg} /$ day was deemed necessary, the subject was withdrawn from the study.

Seizure-free rate was evaluated every 12 weeks after week 24 in the extension phase. Furthermore, a post-hoc analysis was conducted to evaluate the retention rate of lamotrigine monotherapy by estimating the time to withdrawal from the study in the extension phase and plotting by the KaplanMeier method. Subjects who withdrew from the study were handled as event and subjects who completed the study as censored in the Kaplan-Meier analysis. All emergent physical and neurological abnormalities were recorded as adverse events.

The study was conducted in accordance with the International Conference on Harmonization Good Clinical Practice and the principles of the Declaration of Helsinki, after obtaining approval from the institutional review boards at all sites.

\section{Results}

After completing the maintenance phase of the initial study, 22 Japanese patients were enrolled in the extension phase. Sixteen patients had partial seizures (with or without secondarily generalized seizure) and 6 patients had generalized tonic-clonic seizures before entry in the study (Table 1). In addition, the proportion of patients who were seizure-free during 3 months before enrolment 
Table 1. Demographics and other baseline characteristics.

\begin{tabular}{|c|c|c|}
\hline & & $\begin{array}{l}\text { Lamotrigine } \\
(\mathrm{N}=22)\end{array}$ \\
\hline Sex, n (\%) & & \\
\hline Female & & $9(41)$ \\
\hline Male & & $13(59)$ \\
\hline Age & & \\
\hline Mean (SD & & $34.4(20.46)$ \\
\hline Median (n & nin-max) & $24.0(16-80)$ \\
\hline Height $(\mathrm{cm})$ & & \\
\hline Mean (SD & & $164.6(8.74)$ \\
\hline Median (n & nin-max) & $166.5(148-176)$ \\
\hline Weight $(\mathrm{kg})$ & & \\
\hline Mean (SD & & $61.0(15.4)$ \\
\hline Median (n & nin-max) & $59.2(37.5-105.0)$ \\
\hline Race, n (\%) & & \\
\hline Asian-Jap & anese & $22(100)$ \\
\hline History of sei- & $\begin{array}{l}\text { Newly diagnosed } \\
\text { epilepsy }\end{array}$ & $19(86)$ \\
\hline & Recurrent epilepsy & $3(14)$ \\
\hline $\begin{array}{l}\text { Number of seizures } \\
\text { lamotrigine dosing }\end{array}$ & during 6 months be & fore initiation of \\
\hline Partial seizures & $\mathrm{n}$ & 16 \\
\hline (including second- & Mean (SD) & $36.9(85.21)$ \\
\hline $\begin{array}{l}\text { ar1ly generalized } \\
\text { seizure) }\end{array}$ & Median (min-max) & $3.0(2-331)$ \\
\hline & $\mathrm{n}$ & 6 \\
\hline Generalized tonic- & Mean (SD) & $3.2(1.94)$ \\
\hline & Median (min-max) & $2.5(2-7)$ \\
\hline
\end{tabular}

in the extension study was $86.4 \%(19 / 22$ patients). Twelve patients continued the extension study until the monotherapy indication was approved in Japan. Ten patients withdrew from the study. The reasons of withdrawal were adverse events in 2 patients, lack of efficacy in 2, meeting withdrawal criteria in 1, investigator's judgment in 4 , and withdrawal of consent in 1 . The details of investigator's judgment were as follows: two patients could not continue visit to the clinic for personal reasons, and two patients could not continue the study because of investigator's retirement. The longest period of lamotrigine administration was 1055 days.

The seizure-free rates (number of subjects who were seizure-free during the period since the last visit/number of subjects remaining in the study on the date of each visit) determined every 12 weeks beginning on week 24 of the extension phase for all seizure types were as follows: $84.2 \%$ at week $24,94.7 \%$ at week 36 , and $100.0 \%$ at week 48 and all subsequent time points (Table 2). The seizurefree rates by seizure type (compared with the same seizure type during 6 months before the initiation of lamotrigine administration) were as follows: $92.3 \%$ for partial seizures and $83.3 \%$ for primary generalized tonic-clonic seizures at week 24 of the extension phase; and $100.0 \%$ for both seizure types at week 36 and all subsequent time points in the extension phase (Table 3).

Table 2. Seizure-free rate for all seizure types in the extension phase.

\begin{tabular}{|c|c|c|c|}
\hline $\begin{array}{c}\text { Visits during } \\
\text { extension } \\
\text { phase }\end{array}$ & $\begin{array}{c}\text { Number of } \\
\text { subjects } \\
\text { remaining } \\
\text { in the } \\
\text { study on } \\
\text { the date of } \\
\text { each visit }\end{array}$ & $\begin{array}{c}\text { Number of } \\
\text { subjects } \\
\text { who were } \\
\text { seizure-free } \\
\text { during the } \\
\text { period be- } \\
\text { fore each } \\
\text { visit }\end{array}$ & $\begin{array}{c}\text { Seizure-free rate } \\
\text { (\%) } \\
(95 \% \text { confi- } \\
\text { dence interval) }\end{array}$ \\
\hline Week 24 & 19 & 16 & $\begin{array}{c}84.2 \\
(60.42,96.62)\end{array}$ \\
\hline Week 36 & 19 & 18 & $\begin{array}{c}94.7 \\
(73.97,99.87)\end{array}$ \\
\hline Week 48 & 18 & 18 & $\begin{array}{c}100.0 \\
(81.47,100.00)\end{array}$ \\
\hline Week 60 & 16 & 16 & $\begin{array}{c}100.0 \\
(79.41,100.00)\end{array}$ \\
\hline Week 72 & 15 & 15 & $\begin{array}{c}100.0 \\
(78.20,100.00)\end{array}$ \\
\hline Week 84 & 14 & 14 & $\begin{array}{c}100.0 \\
(76.84,100.00)\end{array}$ \\
\hline Week 96 & 11 & 11 & $\begin{array}{c}100.0 \\
(71.51,100.00)\end{array}$ \\
\hline Week 108 & 8 & 8 & $\begin{array}{c}100.0 \\
(63.06,100.00)\end{array}$ \\
\hline Week 120 & 2 & 2 & $\begin{array}{c}100.0 \\
(15.81,100.00)\end{array}$ \\
\hline
\end{tabular}


Table 3. Seizure-free rate by seizure type in the extension phase.

\begin{tabular}{|c|c|c|c|c|}
\hline $\begin{array}{l}\text { Visits } \\
\text { during } \\
\text { the ex- } \\
\text { tension } \\
\text { phase }\end{array}$ & $\begin{array}{c}\text { Seizure } \\
\text { type* }\end{array}$ & $\begin{array}{l}\text { Number } \\
\text { of sub- } \\
\text { jects re- } \\
\text { maining } \\
\text { in the } \\
\text { study on } \\
\text { the date } \\
\text { of each } \\
\text { visit }\end{array}$ & $\begin{array}{l}\text { Number of } \\
\text { subjects } \\
\text { who were } \\
\text { seizure } \\
\text { free during } \\
\text { the period } \\
\text { before } \\
\text { each visit }\end{array}$ & $\begin{array}{c}\text { Seizure-free } \\
\text { rate }(\%) \\
(95 \% \text { confi- } \\
\text { dence interval })\end{array}$ \\
\hline \multirow{2}{*}{ Week 24} & PS & 13 & 12 & $\begin{array}{c}92.3 \\
(63.97,99.81)\end{array}$ \\
\hline & PGTC & 6 & 5 & $\begin{array}{c}83.3 \\
(35.88,99.58)\end{array}$ \\
\hline \multirow{2}{*}{ Week 36} & PS & 13 & 13 & $\begin{array}{c}100.0 \\
(75.29,100.00)\end{array}$ \\
\hline & PGTC & 6 & 6 & $\begin{array}{c}100.0 \\
(54.07,100.00)\end{array}$ \\
\hline \multirow{2}{*}{ Week 48} & PS & 13 & 13 & $\begin{array}{c}100.0 \\
(75.29,100.00)\end{array}$ \\
\hline & PGTC & 5 & 5 & $\begin{array}{c}100.0 \\
(47.82,100.00)\end{array}$ \\
\hline \multirow{2}{*}{ Week 60} & PS & 11 & 11 & $\begin{array}{c}100.0 \\
(71.51,100.00)\end{array}$ \\
\hline & PGTC & 5 & 5 & $\begin{array}{c}100.0 \\
(47.82,100.00)\end{array}$ \\
\hline \multirow{2}{*}{ Week 72} & PS & 10 & 10 & $\begin{array}{c}100.0 \\
(69.15,100.00)\end{array}$ \\
\hline & PGTC & 5 & 5 & $\begin{array}{c}100.0 \\
(47.82,100.00)\end{array}$ \\
\hline \multirow{2}{*}{ Week 84} & PS & 9 & 9 & $\begin{array}{c}100.0 \\
(66.37,100.00)\end{array}$ \\
\hline & PGTC & 5 & 5 & $\begin{array}{c}100.0 \\
(47.82,100.00)\end{array}$ \\
\hline \multirow{2}{*}{ Week 96} & PS & 7 & 7 & $\begin{array}{c}100.0 \\
(59.04,100.00)\end{array}$ \\
\hline & PGTC & 4 & 4 & $\begin{array}{c}100.0 \\
(39.76,100.00)\end{array}$ \\
\hline \multirow{2}{*}{$\begin{array}{c}\text { Week } \\
108\end{array}$} & PS & 4 & 4 & $\begin{array}{c}100.0 \\
(39.76,100.00)\end{array}$ \\
\hline & PGTC & 4 & 4 & $\begin{array}{c}100.0 \\
(39.76,100.00)\end{array}$ \\
\hline \multirow{2}{*}{$\begin{array}{c}\text { Week } \\
120\end{array}$} & PS & 1 & 1 & $\begin{array}{c}100.0 \\
(2.50,100.00)\end{array}$ \\
\hline & PGTC & 1 & 1 & $\begin{array}{c}100.0 \\
(2.50,100.00)\end{array}$ \\
\hline
\end{tabular}

*: Seizures that occurred in the past 6 months before initiation of lamotrigine dosing.

PS: partial seizures (with or without secondary generalized seizure), PGTC: primary generalized tonic-clonic seizures
At week 36 and thereafter in the extension phase, no subjects had seizures of the same type experienced during 6 months prior to the start of study treatment. Seizures occurred in the extension phase in 5 subjects: only once in 3 subjects who continued the study, and more than once in 2 subjects who withdrew from the study for lack of efficacy. KaplanMeier plot of the time to withdrawal from the study in the extension phase is shown in Figure 1.

New adverse events occurring in 2 or more subjects after the end of the maintenance phase of the initial study [1] were nasopharyngitis $(\mathrm{n}=2)$, abdominal pain upper ( $\mathrm{n}$ $=2)$, abdominal pain $(\mathrm{n}=2)$, and contusion $(\mathrm{n}=2)$. All adverse events in the extension phase were mild or moderate in severity. Rash-related adverse events were reported in 3 subjects. One of 3 rash-related adverse events was related to the investigational drug and resulted in withdrawal from the study. Another adverse event that led to withdrawal from the study was Brugada syndrome, which was considered to be unrelated to the investigational drug.

Serious adverse events occurred in only one patient (pulmonary contusion resulting from a motor vehicle accident, epilepsy that required hospitalization) in the extension phase. These events occurred separately. The patient recovered, and the investigator regarded the events to be unrelated to the investigational product. No deaths and no suiciderelated adverse events occurred.

\section{Discussion}

We have previously reported the efficacy 


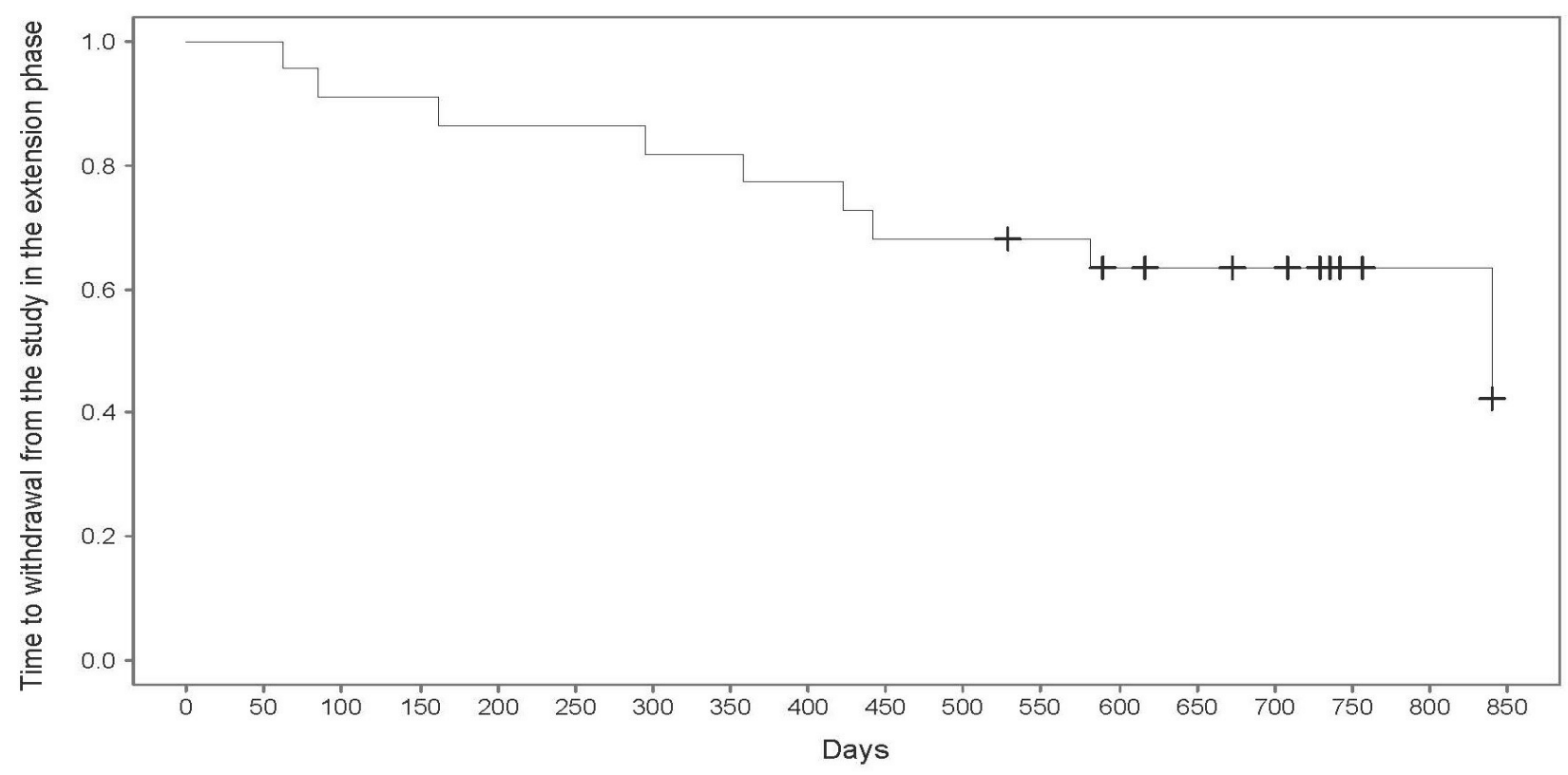

Figure 1. Kaplan-Meier plots of time to withdrawal from the study in the extension phase. + indicates a subject who completed the study.

and safety of lamotrigine monotherapy for up to 30 weeks of treatment in Japanese and Korean patients with newly diagnosed epilepsy or recurrent epilepsy [1]. Twenty-two Japanese patients who completed the initial study were enrolled in the extension phase. More than $80 \%$ of Japanese patients who remained in the extension study at each time point achieved seizure-free status at all time points up to week 120 of the extension phase. After week 48 , the seizure-free rate was $100 \%$. All seizure types and each seizure type were well controlled. The retention rate was over $60 \%$ at 2 years from the initiation of the extension phase.

No unexpected adverse events were reported in the extension phase. The types of adverse events observed were consistent with those reported during the first 30 weeks of treatment in the initial study [1] and a previous long-term study of lamotrigine in Japa- nese patients with bipolar disorders [2]. Rashrelated and drug-related adverse events were reported in one patient at cumulative day 239 after lamotrigine was started. The patient was immediately withdrawn from the study and the events were resolved after lamotrigine discontinuation. The dose of lamotrigine had not been altered before or around the time of appearance of the rash. Lamotrigine should be discontinued at the first sign of rash to prevent further aggravation, unless the rash is clearly not drug-related by a physician's judgment. Although the rash typically occurs within the first 8 weeks of lamotrigine administration [3], alertness to the possibility of late onset rash is also needed.

The National Institute for Health and Care Excellence (NICE) [4] recommends carbamazepine or lamotrigine as first-line treatment in adults with newly diagnosed focal seizures (partial seizures). For generalized tonic- 
clonic seizures, lamotrigine is recommended if sodium valproate is unsuitable. In Japan, the Clinical Practice Guideline for Epilepsy [5] recommends lamotrigine as treatment for newly diagnosed partial seizures and generalized tonic-clonic seizures in adults.

Limitations of our trial include the open label design, small sample size $(\mathrm{n}=22)$, and the lack of a control group. In addition, the retention rate is low for patients who entered the extension phase. However, despite these limitations, our findings suggest that longterm administration of lamotrigine monotherapy in Japanese patient is effective and generally well tolerated.

In conclusion, long-term lamotrigine monotherapy appears to be effective in Japanese patients with newly diagnosed or recurrent epilepsy manifesting partial seizures and generalized tonic-clonic seizures, and the longterm safety profile is similar to that previously reported.

\section{Acknowledgements}

The study was sponsored and funded by GlaxoSmithKline (GSK). GSK clinical study identifier was LAM115376. Takamichi Yamamoto has received speaker's honoraria from GlaxoSmithKline and Otsuka Pharmaceutical. Masahiro Shimizu, Katsuaki Sato, and Atsuyo Kurata are employees of GSK. Yotaro Numachi is an employee and shareholder of GSK.

\section{Appendix 1}

Members of the lamotrigine monotherapy study group included the following investigators. For each site, the principal investigator is listed first, followed by sub-investigators.
T. Yamamoto, A. Fujimoto, R. Kobayashi, H. Nakatogawa (Seirei Hamamatsu General Hospital); K. Kashihara, T. Imamura (Okayama Kyokuto Hospital); K. Tamura, E. Boku, H. Nakase (Nara Medical University Hospital); M. Nakano, M. Moriya, M. Sato, T. Yamanaka (Toyonaka Municipal Hospital); M. Sasagawa, H. Masuda, S. Kameyama, H. Murakami, H. Shirozu, N. Hasegawa (Nishi-Niigata Chuo National Hospital); S. Igarashi, H. Ouchi, A. Sato, T. Sato, J. Shinbo (Niigata City General Hospital); N. Nakasato, H. Itabashi, K. Jin, Y. Kakisaka (Tohoku University Hospital); N. Akamatsu, T. Yuhi, T. Shozaki, A. Tanaka, T. Toyota, U. Takechi (University Hospital of Occupational and Environmental Health); S. Tanaka (Tanaka Neurosurgical Clinic).

\section{References}

[1] Yamamoto T, Hong SB, Shimizu M, Sato K, Numachi Y. Lamotrigine monotherapy in newly diagnosed epilepsy or recurrent epilepsy: A multi-center, open-label study. Epilepsy \& Seizure 2014; 7: 55-65.

[2] SCA106052, the GSK Clinical Study Register, Available at URL (2016.7): https://gsk.sylogent.com/files/6f5a34a72b5c-4b93-a136-b65c64b6c7ee

[3] Messenheimer J, Mullens EL, Giorgi L, Young F. Safety review of adult clinical trial experience with lamotrigine. Drug Saf 1998; 18: 281-296.

[4] National Institute for Health and Care Excellence (NICE). Epilepsy overview: Anti-epileptic drugs (AEDs) to offer based on presenting epilepsy seizure type(s). Available at URL (2016.7): 
http://pathways.nice.org.uk/pathways/ epilepsy/anti-epileptic-drugs-aeds-tooffer-based-on-presenting-epilepsyseizure-types

[5] Japanese Society of Neurology. Clinical Practice Guideline for epilepsy 2010. Available at URL (2016.7): http:// www.neurology-jp.org/guidelinem/epgl/ sinkei_epgl_2010_04.pdf 